\title{
The Nursing Documentation Dilemma in Uganda: Neglected but Necessary. A Case Study at Mulago National Referral Hospital
}

\author{
Grace Mary Nakate1, Diane Dahl2, Pammla Petrucka',4, Karen B. Drake5, Ruby Dunlap6 \\ ${ }^{1}$ Aga Khan University, Advanced Nursing Studies, Kampala, Uganda \\ ${ }^{2}$ College of Adult Professional Studies, Bethel University, St. Paul, USA \\ ${ }^{3}$ College of Nursing, University of Saskatchewan, Regina, Saskatchewan, Canada \\ ${ }^{4}$ Academics without Borders - Volunteer with Aga Khan University, East Africa \\ ${ }^{5}$ Department of Nursing, Bethel University, St. Paul, USA \\ ${ }^{6}$ Belmont University, Nashville, TN, USA \\ Email: grace.nakate@aku.edu,diane-dahl@bethel.edu,pammla.petrucka@usask.ca,k-drake@bethel.edu \\ ruby.dunlap@belmont.edu
}

Received 5 November 2015; accepted 15 December 2015; published 18 December 2015

Copyright (C) 2015 by authors and Scientific Research Publishing Inc.

This work is licensed under the Creative Commons Attribution International License (CC BY). http://creativecommons.org/licenses/by/4.0/

(c) (i) Open Access

\begin{abstract}
In Uganda, nursing documentation still remains a challenge, in most of the government hospitals and some private hospitals, it remains at a manual (non-technology driven) level and omissions have been observed. Nurses continue to capture standard elements in their documentation. A mixed methods intervention study was conducted to determine knowledge and attitudes of nurses towards documentation, including an evaluation of nurses' response to a designed nursing documentation form. Forty participants were selected through convenience sampling from six wards of a Ugandan health institution. The study intervention involved teaching nurses the importance of documentation and using of the trial documentation tool. Pre- and post-testing and open-ended questionnaires were used in data collection. The results from the close-ended questions were presented in the previous publication; the responses from the open-ended questions would then be presented. The open-ended questions regarding comments about the nursing documentation process and suggestions about the process of implementing the nursing documentation system in the ward units were considered. All participants were provided the opportunity to provide personal comments, reflections, or stories of their experiences with documentation in patient care. A thematic analysis approach was used during data analysis. The results showed that the participants had positive attitude towards documentation of patient care, but they had constraints limiting them to document, they reflected issues concerning the perceived pressure from the administra-
\end{abstract}


tions and support to document. The study findings have implication that there is need for organizational support and to have multisite studies and extension of the documentation tool.

\title{
Keywords
}

\author{
Nursing Documentation, Qualitative Researcher, Nursing Records, Uganda Healthcare
}

\section{Introduction}

How often are we told, as nurses, "not documented, not done!”? Although this may be a simple cliché, these four simple words are at the crux of a serious gap in patient care which rests in the lack, incompleteness, and even absence of documentation of nursing care.

So what is nursing documentation? It is either manual or electronic data which primarily communicates patient information to the healthcare team. Documentation must accurately and thoroughly reflect the nursing process by capturing elements of nursing assessment and diagnosis, nursing interventions, nursing care implementation and evaluation, and ultimately, patient response and outcomes [1]. Some of the most common reasons cited for nursing documentation are: to facilitate communication and collaboration [2]-[4]; to promote the visibility and continuum of nursing care [2] [5] [6]; to facilitate patient care decisions and safety [7]; to meet professional, regulatory, and legal standards [8]-[11]; and to facilitate evidence based processes such as resource management and infection control strategies [12].

Yet, documentation is one of the most disputed and questioned nursing roles, variably interpreted as accurate and evidentiary nursing actions or summarily dismissed as a misrepresentation of nursing care [13]. Documentation is one of the care aspects that often are not prioritized in the effort to manage the care environment [14]. The amount of time and effort spent on documentation is variably reported with ranges from $15 \%-20 \%$ [15] to $25 \%-50 \%$ [16]. The literature is replete with examples of barriers and challenges to nursing documentation [17] [18]. Some speak to time and resource constraints (i.e., workload) as major impediments to meeting the documentation expectations [19] [20]. Others cite lack of organizational commitment and institutional policies to the process as a significant barrier [9]. Taylor (2005) emphasized that the lack of standards and no single model for health records reflected a systemic deficit in documentation [21]. Still others speak of lack of professional standards and structures for documentation [19]. According to Papathanassiou, Kotrotsiou and Bletsa (2007), "the importance of nursing documentation is neuralgic, provided that without it, there cannot be a complete qualitative nursing intervention and not even effective care for the patient” ([22], p. 30).

There are clear indications from the evidence that a number of strategies may mitigate or address the challenges to documentation. According to Pelletier, Duffield, and Donoghue (2005), there is a need to adopt a documentation system which is efficient and easy to achieve [23]. Wood (2002) emphasizes that nurses must see the value in documentation as part of their professional practice, which is places responsibility in the realm of the professional bodies and educational institutions [24]. Such recognition addresses the need to see documentation as a legal effort [25]. Others suggest that continuing education is necessary to ensure that documentation is made a priority [17] [26].

Few articles consider the issue of documentation in developing countries given the pre-eminent presence of research on the consequences of insufficiency of nurses and resources as well as workplace inadequacies. Bakken (2007) alludes to under qualified nursing staff, lack of reimbursement, and non-accreditation as contributing to inefficient documentation in these contexts [9]. Others [27] have also suggested that the lack of documentation standards, lack of recognition of relevance of documentation, and lack of an enabling legal environment are more prominent in developing contexts. More recently, the emphasis has leaned towards the potential for technology based documentation such as electronic health records in developing countries [28]-[33].

Nursing documentation in Uganda remains rudimentary. Exclusively paper based, there are few standards for documentation and even less evidence of consistent documentation by nurses. The focus remains primarily on assessments and vital signs with some customization in specialty units (such as partograms and test results). Most notably, there are limited critical reflections on the nature and outcomes of nursing care for the patients.

In this study at one Ugandan hospital, the knowledge and attitudes about documentation by a select group of 
Ugandan nurses were sought. In a previous article, the description and findings of a pilot intervention and documentation tool were reported [34]. The qualitative component of this study captures the nurses' voices on their experiences, perceptions, and preferred futures for documentation in their patient care environment.

\section{Methods}

\subsection{Research Design}

The study in its entirety was a quasi-experimental interventional study occurring in late 2010. The quantitative methods and findings are reported in a prior publication [34]. The qualitative component of this sequential mixed methods study was reflected in open ended questions regarding knowledge and attitudes towards documentation included with both self-administered pre and post-tests. All participants were provided the opportunity to provide personal comments, reflections, or stories of their experiences with documentation in patient care.

\subsection{Ethical Considerations}

Study approval was obtained from Uganda Christian University (UCU) Research and Ethics Committee and Research and Ethical committee of the Mulago National Referral Hospital where the research was conducted. An introductory letter from the Department of Health Science in the Nursing Program at UCU Mukono was obtained to introduce the researcher to the Hospital Research Committee. A written consent was given to the study participants and their consent sought prior to their involvement in the study. Privacy and confidentiality was ensured and participants were informed that their participation in the study was voluntary and that they had the right to refuse to participate or to withdraw without affecting their relationship with the hospital administration.

\subsection{Sample}

The study target population was all registered nurses and midwives at the Mulago National Referral Hospital currently working on one of two general medical, two general surgical, or two obstetrics/gynecology wards. In total, 80 nurses met the inclusion criteria of: professional nursing credential (i.e., enrolled, registered, or graduate nurses); tenure of experience ( $>2$ years); and volunteering to participate. Through a convenience sampling approach, 37 individuals participated in the study.

\subsection{Data Collection and Analysis}

The self-administered questionnaire, which was repeated pre and post intervention, was constructed in three parts. Part One reflected participant demographics including personal, educational, and, occupational elements. Part Two explored knowledge and attitudes through multiple choice questions and a Likert tool [34] respectively. Part Three offered two open ended questions on knowledge and attitudes regarding nursing documentation in their practices. The first question asked participants to provide "(Do you have) any comments about the nursing documentation process" and the second probed "(Do you have) any suggestions about the process of implementing a nursing documentation system in your ward unit”.

The researcher followed a thematic analysis approach similar to that described by other researchers [35] [36]. First, all responses were reviewed to become familiar with the data through immersion. Preliminary themes were derived inductively through an iterative process of reading, reflecting, and coding. These were then refined and reflected through a series of exemplars (quotations) and sub-theme clusters.

\section{Findings}

\subsection{Characteristics of the Participants}

Participants were all female between the ages of 28 and 58 with the mean age of 43.24 years. Three participants were degree prepared and the remaining 34 were equally certificated or diploma prepared. Approximately twothirds were registered nurses or nurse/midwives. $35 \%$ of participants came from each of the medical and surgical wards with the remaining 30\% from the obstetrics/gynecology wards. Eight respondents (21.6\%) had 6 - 10 years of ward experience, 4 (10.8) had 11 - 15 years, and the remaining 25 (67.5\%) reported 16 plus years of ward nursing experience. 


\subsection{Thematic Analysis}

On review, the responses in the pre and post-tests did not differ. More responses were related to the second question on suggestions for a documentation system. Three major themes and 10 sub-themes emerged, which were briefly reported previously [34]. The first theme was labelled "importance of documentation" which encompassed 2 sub-themes- "influence on daily practice and professional roles" and "influence on institutional issues". The second theme was labelled "challenges" which encompassed 5 sub-themes-"organizational issues", "knowledge on documentation", "training”, "motivation/support from nursing leadership", and "motivation/responses from the interdisciplinary team". The third theme was labelled "solutions" which encompassed 3 sub-themes_-"motivational factors", "educational factors", and "facilitating factors".

\subsubsection{Theme 1: Importance of Documentation}

As participants reflected on the documentation, words, such as "helpful", "good", "improves" and "professional", were dominant. Additionally, the respondents clearly separated their practice from the institutional practices, resulting in the two sub-themes.

Sub-Theme 1: Influence on daily practices and professional roles. From the professional level, nurses spoke about the documentation routines in their practices. They referred to documentation as allowing them to "individualize care" and to "identify the outcome of the care provided". A number of respondents spoke about the effect of documentation on direct patient care and the relationship between nurses and patients. As stated by one participant "Documentation is good, especially when assessing patients to identify their problems". Some indicated that documentation guided their care as a "reminder of procedures to be done". Another spoke of how documentation "improves patients' follow-up". Documentation is attributed with a critical role in relationship building between patients and nurses. It leads to "patients (being) checked on from time to time in an effort to identify the outcome of the care provided". Most participants indicated that documentation informs the collaborative health team about what has been done for the patients, thus promoting continuity of care. Some indicated that documentation is an accountability tool, which enables them to account for time spent with their patients. This is reflected in the following comment: "When I document, my supervisors can tell how much time I have spent with the patient (but) in our present practice the time we spend with patients is not accounted for."

Participants spoke about other accountabilities beyond their time, such as medication dispensing and clinical performance. A number of participants spoke about nursing documentation potentially being used in courts to defend nurses against litigation.

Sub-Theme 2: Influences on institutional issues. From the institutional perspective, participants indicated that the institution's credibility is entwined with documentation. This is reflected in the comment "The credibility of the hospital can be gauged from the quality of the nurses' documentation.” This sense of protection and reputation carried forward in discussions relating to improved professional nurse-patient relationships and overall perceptions of quality of care. Participants recognized that "When we start documenting patient care, the quality of care the patients receive will be determined by the nurses' records because they stay with the patients most of the time”. So, the obvious desire and preferred future to improve the quality and nurses' capacity for documentation as well as the positive impacts of such efforts was evident in the participants' remarks. This was clearly reflected in the comment by one participant that "When we document the care provided, we shall be seen to be working as a profession."

\subsubsection{Theme 2: Challenges}

As the participants reflected on documentation in their current context, a number of potential barriers and deficiencies were identified. These were clustered into five sub-themes which will be discussed herein.

Sub-Theme 1: Organizational Issues. The participants spoke of their environment as replete with challenges. Lack of time for documentation was couched with the discussion of excessive workload as reflected in the following comments: "Nursing documentation takes a lot of time and yet I have a big number of patients to take care of, if I document the care that I give to each one of the patients I will not be able to treat all the patient in my care." and "...It's not easy for one person to take care of 50 patients, and then one expects you to document all the care that you give to the patients."

A number of participants felt constrained or frustrated by the structural set up in the ward as a deterrent to documentation. One individual stated that: "The administration should devise ways of reducing the overcrowd- 
ing on the ward units because it demotivates the nurses and it becomes very difficult to document care when the ward unit is full with limited space.”

The lack of resources and supplies extends beyond human resources. One participant indicated that the lack of stationary and basic monitoring equipment impact documentation as it deters from "the nurses' practice of taking observations and recording them." This is further reflected in the comment that: "If I do not take the patient's blood pressure and temperature, then what should I document about the patient?"

Without designated nursing documentation forms, participants felt that they were disadvantaged and unable to fully document. As well, it takes a lot of time to create or design a reporting system in an era where there is a shortage of staff and increasing workload.

Sub-Theme 2: Knowledge on Documentation. A number of participants indicated that many nurses were not conversant on the nursing documentation process. One individual stated: "I don't see (documentation) being done in my unit probably because the nurses are not knowledgeable about the nursing process and they don’t seem to realize the importance of nursing documentation".

Sub-Theme 3: Training. The participants acknowledged that, at the diploma level, students are taught the nursing process. However, they also stated that nobody follows up after training to ensure that they are documenting. One participant stated that: "If nursing documentation is not emphasized in the training schools, the students will not document after qualifying as a nurses."

Sub-Theme 4: Support from Nursing Leadership. Some participants stated that the nursing leaders have not put much emphasis on nursing documentation; they stated that due to the work overload and short staffing on the ward units the nurses need a constant remainder from the nursing leaders. One participant stated, "If nobody bothers to ask for the nurses' documentation notes and even when they document nobody bothers to find out whether the documentation was satisfactory, the nurses will not document."

Sub-Theme 5: Motivation from the Interdisciplinary Team. A few participants stated that nobody reads the nurses notes. Some participants acknowledged that some members of the interdisciplinary team are skeptical about the idea of the nurses documenting in patients' clinical notes. One participant stated: "The doctors do not trust the quality of the nursing notes.”

In general, the participants stated that lack of knowledge on documentation, and lack of support and motivation from the nursing leadership and the interdisciplinary team negatively affects implementation of the documentation process.

\subsubsection{Theme 3: Solutions}

The participants made several suggestions about a formal documentation system in the ward units. Their responses are grouped into the following sub themes: motivating factors; educational factors; and facilitating factors.

Sub-Theme 1: Motivating Factors. A number of comments were respecting motivation from nursing leadership with respect to documentation. The emphasis was on the imperative for nursing leadership to deal with the overcrowding and workload management in order to free up nurses to appropriately document the care. "The administration should devise ways of reducing the overcrossing on the ward units because it demotivates us as bedside nurses; it becomes very difficult to document care.” Other participants suggested that the nursing leaders should continuously encourage the nurses to document patient care and should make the policy guidelines available for the nurses on the ward units. As a participant stated: "The documentation process will only be embraced if the nursing administration puts in more effort to emphasize the need for the nurses to document patient care regularly." Another one cautioned that: "The nursing leaders should encourage us to document patient care without forcing us to do so, that's when the system will be sustained. This is something new to us we need time to get used to it."

Generally, there was an interest in proper practices such as auditing of files on a regular basis as part of supportive supervision. Motivation from the interdisciplinary team was also mentioned as important, especially shifting from the current lack of use of nursing notes by physicians. "There should be some encouragement from the doctors, they should always read the nursing notes ... should encourage nurses to document care..."

Sub-Theme 2: Educational Factors. In terms of education, the nurses spoke about both pre-service and continuous education needs for documentation. A few participants mentioned that nursing schools play a key role in documentation becoming embedded in the future practice environment. "If the documentation is not emphasized in the training schools, the students will not document after qualifying as nurses.” 
In terms of continuing nursing education, participants suggested that workshops be organized to update the knowledge of the ward in charges on documentation of patient care. They stated: "The ward in charges is the consultant on the ward units, therefore they should be well conversant with the documentation system if it's to be sustained in this hospital." Others indicated that: "The continuous nursing education on documentation should be done as a routine in an effort to encourage the nurse to document patient care."

Sub-Theme 3: Facilitating Factors. Creation of a uniform documentation system was suggested by some participants as a potential solution. "...I realize that there is some kind of documentation done by the nurses... however, this needs to be uniform such that we come up with one way of reporting patients' information.”

Almost all participants recommended that the hospital should make available equipment for assessing the patients' vital signs and stationary to record findings in order to inspire nurses to document the observations. Some participants stated that the policies on nursing documentation should be made available on the ward units to support the nurses in documenting care. Others suggested that documentation of patient care should be made compulsory. They further stated that: "If documentation is to be implemented in the ward units, the implementation process should be done simultaneously on all ward units." Another participant suggested that: "policy makers should get involved in the implementation of the (nursing) documentation system in this country."

\section{Discussion}

This study was based on the primary data collected from the nursing staff working on six selected ward units at Mulago National Referral Hospital. At total of 37 mid-career (5 plus years of service) female nurses or nurse/ midwifes participated in the study.

Regarding the comments of the participants about the nursing documentation, the responses from the participants were organized into themes and subthemes most of the responses from the pre-test and post-test were similar. The three themes identified were: Importance of documentation, challenges, and solution to the challenges.

In reflecting on Theme One (Importance of Documentation), most participants at least knew some advantages of nursing documentation process. The first sub-theme-Influence on Daily Practice and Professional Roles encompassed reflections concerning how the documentation routines affected direct patient care, the nurses' conduct in relation to the patient, and changes in the professional focus as well as practice routines. The participants stated that documentation improves the quality of care rendered to the patients, it improves the nurse-patient relationship, it improves follow up of the patients, and it enhances continuity of patient care. These finding concur with the participants' responses on attitude test in this study and they are in line with Cheevakaemaoo, et al. (2006) who described the importance of documentation in the nursing profession [9]. Further, the participants are aware of the effect documentation on the daily clinical activities.

In addition, most of the participants stated that documentation informs the collaborative health care team about what has been done for the patients and the outcomes thus promoting continuity of care. Statements that, documentation helps the nurses to account for the time they spend with the patients providing care were stated. Others stated that it helps the nurses to account for the drugs they dispense to the patients, and also to assess their performance in the clinical area through audits of patients' files. Most of them reported that the nursing documentation can be used in the courts of law to defend nurses against litigation. Furthermore, they pointed out that documentation creates a data base for students learning. This is in line with Potter and Perry (2009), who stated that nursing documentation covers a wide variety of issues, topics, and systems like legal requirements, accreditation, accountability, financial billing, and communication [37]. The second sub-theme-Institutional Issues - revealed that participants felt that good documentation improves the credibility of the institution, and it makes the nursing profession visible. They pointed out that the quality of care provided to the patients in an institution can be evaluated using the nursing documentation records. There is a positive correlation between the records and the quality of care [38].

The participants' description of the importance of documentation indicated that they were knowledgeable about the importance of documentation to the nursing profession. The statements about the importance of nursing documentation were positive and showed a good understanding of the advantages of documenting patient care. This level of knowledge was also described in a study on improving documentation using a nursing model where the participants displayed a high level of knowledge on the topic of implementation of nursing documentation [38].

The second theme (Challenges) revealed a complex array of issues and concerns (i.e., 5 sub-themes) ranging 
from organizational issues to leadership and inter-disciplinary team support. From the sub-theme respecting organizational issues, participants cited lack of time as a major issue in this study, mirroring findings in many previous studies [20] [38] [39]. The participants in the current study stated that they had a heavy workload with the patients; this workload does not allow them time to document patient care. They added that the increasing workload was not matched with increase in the staffing, which hindered the implementation of innovations within nursing [38]. Participants showed concern that inconsistency in supplies and equipment contribute to lack of adherence to documentation of patient care. The second sub-theme respecting knowledge on documentation highlighted that participants were not familiar with documentation processes, which aligns with Werner's (2004) finding that without this knowledge, nurses will not carry out documentation [40]. The third sub-theme of training linked the need for pre-service training and ongoing continuous education in documentation with future practice. Sub-themes four and five related to support from nursing and inter-disciplinary teams for nursing documentation. Some participants stated that the nursing leadership has not put much emphasis on nursing documentation; they stated that due to the work overload and short staffing on the ward units the nurses need a constant remainder from the nursing leaders. This is in line with the findings on a survey to determine the extent of the problem in nursing documentation which found that most nurses appeared to be aware of the importance of documentation of patient care, but the motivation to do so in a busy schedule where documentation could take away time from direct patient care was lacking to some degree [39]. A few participants stated that nobody reads the nurses notes. This may be due to the fact that nursing has not yet developed a standardized documentation system where the comprehensive nursing report may be missing. Patients' records are communication tools which should contain up-to-date information about their health status [41]. This information should be used by all health professionals.

In Theme 3 (Solutions), the participants made several suggestions about the introduction of the documentation system in the ward units. Their responses were grouped into three sub themes: motivational factors, educational factors, and facilitating factors. Motivational factors were attributed to nursing leadership and the interdiscip- linary team in promoting, facilitating, and created a conducive environment for nursing documentation. The participants emphasized that improvements in the work environment (such as reducing overcrowding) is critical to increasing the compliance with documentation. Additionally, supportive supervision for documentation would positively advance the documentation. One study noted that bedside nurses need to feel that ward management and hospital management continuously support the efforts made to change the documentation system [42]. The support may take the form of setting standards and protocols in nursing practice in particular emphasizing documentation of care or an encouragement from the top leaders in the nursing profession. According to the participants, they need support from the interdisciplinary team-specifically the physicians. Werner (2004) stated that the support from the significant others in the nursing profession and outside the profession motivate the nurses to document patient care [40]. In terms of the second sub-theme, the participants suggested that workshops should be organized to update the knowledge of the entire ward in charges and staff nurses on documentation of patient care. A similar view was expressed by Darmer et al. (2004) who state that it was necessary to educate all nurses in the ward simultaneously rather than educating a few key persons and expecting them to effect the desired changes [42]. The final sub-theme emphasizes the need for standardization and enabling policies for documentation to become an embedded tool for patient care. Documentation forms should be user-friendly and their complexity should be kept to a minimum [41]. Currently, the responsibility for policies on nursing documentation remains the purview of the National Council of Nurses and Midwives.

\subsection{Limitations}

The study was a one month involvement, which did not allow the researchers to become full immersed into the organizational culture and may have limited our interpretations. Participation was highly contingent on work schedules and individual perceptions of the importance of documentation. Further, nurses were on very active acute units, hence, their workloads may have prohibited them from participating in this research. The use of questionnaires as the instrument for data collection may have impacted on the depth of information collected especially in terms of acknowledging knowledge and attitudes of the nurse participants.

\subsection{Recommendations}

In terms of the documentation and nursing care, it is important that nursing leadership prioritize the motivation and education of nurses on the relevance and imperative of documentation. Further, nursing schools are encouraged to embed the philosophy and vision that documentation is a key component of patient care in their students 
and faculty members. This foundation will potentiate the compliance and rigor necessary for improving documentation. Future research could explore the use of focused group discussion or in-depth interviews so as to get detailed data on the nurses' attitude toward documentation of patient care. It is important to continue this program of research as nursing documentation is a global concern and imperative.

\section{Conclusion}

The nurses viewed nursing documentation as an important practice towards patient care; though the act of documentation remains problematic. Lack of time and support from the nursing leadership and the interdisciplinary team was the challenge that affected nursing documentation. Other challenges included overcrowding and lack of policies that guided nursing documentation and also the lack of a pre-designed documentation tool for documenting patient care. It was suggested that if these challenges were worked upon, the documentation process would be successfully implemented. Specific suggestions to combat the challenges included providing in-service training courses, increasing support from the nursing leadership and the interdisciplinary team, improving on the staffing level in the health facility, introducing standard documentation tools, and availing the policy guidelines on nursing documentation.

\section{Acknowledgements}

Our thanks go to the Mulago National Referral Hospital management and nurses who gave their time and knowledge to this study.

\section{References}

[1] Higginbotham, E. and McCarthy, R. (2001) Elements of Nursing Negligence. In: O’Keefe, M.E., Ed., Nursing Practice and the Law: Avoiding Malpractice and Other Legal Risks, F.A. Davis Co., Philadelphia, 118-131.

[2] College of Nurses Ontario (2005) Practice Standard: Documentation. College of Nurses Ontario, Toronto.

[3] Nurses Board of South Australia (2006) Guiding Principles for Documentation. Nurses Board of Australia, Adelaide.

[4] Mbabazi, P. and Cassimjee, R. (2006) The Quality of Nursing Documentation in a Hospital in Rwanda. Africa Journal of Nursing and Midwifery, 8, 31-42.

[5] Ofi, B. and Sowunmi, O. (2012) Nursing Documentation: Experience of the Use of the Nursing Process Model in Selected Hospitals in Ibadan, Oyo State, Nigeria. International Journal of Nursing Practice, 18, 354-362. http://dx.doi.org/10.1111/j.1440-172X.2012.02044.x

[6] Pearson, A. (2003) The Role of Documentation in Making Nursing Work Visible. International Journal of Nursing Practice, 9, 271. http://dx.doi.org/10.1046/j.1440-172X.2003.00442.x

[7] Jordan, K.S. (2009) SBAR: A Communication Formula for Patient Safety. http://www.boston.com/jobs/healthcare/oncall/articles/2009/02/17/perspective/

[8] College of Registered Nurses of British Columbia (CRNBC) (2007) Practice Support: Nursing Documentation. College of Registered Nurses of British Columbia, Vancouver.

[9] Cheevakasemsook, A., Chapman, Y., Francis, K. and Davies, C. (2006) The Study of Nursing Documentation Complexities. International Journal of Nursing Practice, 12, 366-374. http://dx.doi.org/10.1111/j.1440-172X.2006.00596.X

[10] Griffith, R. (2004) Putting the Record Straight: The Importance of Documentation. British Journal of Community Nursing, 9, 122-125. http://dx.doi.org/10.12968/bjcn.2004.9.3.12436

[11] International Council of Nurses (2012) The ICN Code of Ethics for Nurses. http://www.icn.ch/who-we-are/code-of-ethics-for-nurses/

[12] Jefferies, D., Johnson, M. and Griffiths, R. (2010) A Meta-Study of the Essentials of Quality Nursing Documentation. International Journal of Nursing Practice, 16, 112-124.

[13] Hearthfield, M. (1996) Nursing Documentation and Nursing Practice: A Discourse Analysis. Journal of Advanced Nursing, 24, 98-103. http://dx.doi.org/10.1046/j.1365-2648.1996.15113.x

[14] Hoban, V. (2003) How to Improve Your Record Keeping. Nursing Times, 99, 78-79.

[15] Moody, L. and Snyder, P.E. (1995) Hospital Provider Satisfaction with a New Documentation System. Nursing Economics, 13, 24-31.

[16] Gugerty, B., Maranda, M.J., Beachley, M., Navarro, V.B., Newbold, S., Hawk, W., et al. (2007) Challenges and Opportunities in Documentation of the Nursing Care of Patients: A Report of the Maryland Nursing Workforce Commission, Documentation Work Group. Maryland Nursing Workforce Commission, Baltimore.

[17] Blair, W. and Smith, B. (2012) Nursing Documentation: Frameworks and Barriers. Contemporary Nurse, 41, 160-168. 
http://dx.doi.org/10.5172/conu.2012.41.2.160

[18] Kärkkäinen, O. and Eriksson, K. (2005) Recording the Content of the Caring Process. Journal of Nursing Management, 13, 202-208. http://dx.doi.org/10.1111/j.1365-2834.2005.00540.x

[19] Bakken, S. (2007) Building Standard-Based Nursing Information Systems. Pan American Health Organization, Washington DC.

[20] Owen, K. (2005) Documentation in Nursing Practice. Nursing Standard, 19, 48-49. http://dx.doi.org/10.7748/ns2005.04.19.32.48.c3846

[21] Taylor, M. (2005) Clinical Record Keeping Guidelines. Primary Care Trust, South Worcestershire. http://www.worcestershirehealth.nhs.uk

[22] Papathanassiou, I., Kotrotsiou, S. and Bletsa, V. (2007) Nursing Documentation and Recording Systems of Nursing Care. ICUS and Nursing Web Journal, 16, 30-31.

[23] Pelletier, D., Duffield, C. and Donoghue, J. (2005) Documentation and the Transfer of Clinical Information in Two Aged Care Settings. Australian Journal of Advanced Nursing, 22, 40-45.

[24] Wood, C. (2003) The Importance of Good Record-Keeping for Nurses. Nursing Times, 99, 26-27.

[25] Ehrenberg, A. and Birgersson, C. (2003) Nursing Documentation of Leg Ulcers: Adherence to Clinical Guidelines in a Swedish Primary Health Care District. Scandinavian Journal of Caring Sciences, 17, 278-284. http://dx.doi.org/10.1046/j.1471-6712.2003.00231.x

[26] Darmer, M.R., Ankerson, L., Nielsen, B.G., Landberger, G., Lippert, E. and Egerod, I. (2006) Nursing Documentation Audit-The Effect of a VIPS Implementation Programme in Denmark. Journal of Clinical Nursing, 15, 525-534. http://dx.doi.org/10.1111/j.1365-2702.2006.01475.x

[27] Pan American Health Organization (1999) Nursing in the Region of the Americas. Washington DC.

[28] Braa, J., Hanseth, O., Mohammed, W., Heywood, A. and Shaw, V. (2007) Developing Health Information Systems in Developing Countries: The Flexible Standards Strategy. MIS Quarterly, 31, 1-22.

[29] Heeks, R. (2002) Information Systems and Developing Countries: Failure, Success, and Local Improvisations. The Information Society, 18, 101-112. http://dx.doi.org/10.1080/01972240290075039

[30] Kossi, E.K., Sæbø, J.I., Braa, J., Jalloh, M.M. and Manya, A. (2012) Developing Decentralised Health Information Systems in Developing Countries_Cases from Sierra Leone and Kenya. The Journal of Community Informatics, 9. http://ci-journal.net/index.php/ciej/article/view/861/1001

[31] Moahi, K.H. (2009) ICT and Health Information in Botswana: Towards the Millennium Development Goals. Information Development, 25, 198-206. http://dx.doi.org/10.1177/0266666909340790

[32] WHO-SEARO Coding Workshop (2007) Guidelines for Medical Records and Clinical Documentation. https://occupationaltherapy2012.files.wordpress.com/2012/03/2007 guidelines for clinical doc.pdf

[33] World Health Organization (2006) Framework and Standards for the Development of Country Health Information Systems. Health Metrics Network, Geneva.

[34] Nakate, M.G., Dahl, D., Drake, K.B. and Petrucka, P. (2015) Knowledge and Attitudes of Select Ugandan Nurses towards Documentation of Patient Care. African Journal of Nursing and Midwifery, 2, 57-65.

[35] Alhojailan, M.I. (2012) Thematic Analysis: A Critical Review of its Process and Evaluation. West East Journal of Social Sciences, 1, 39-47.

[36] Braun, V. and Clarke, V. (2006) Using Thematic Analysis in Psychology. Qualitative Research in Psychology, 3, 77-101. http://dx.doi.org/10.1191/1478088706qp063oa

[37] Potter, P.A., Perry, A.G., Astle, B. and Duggleby, W. (2014) Canadian Fundamentals of Nursing. 5th Edition, Mosby, Toronto.

[38] BjoRvell, C., Wredling, R. and Thorell-Ekstrand, I. (2003) Improving Documentation Using a Nursing Model. Journal of Advanced Nursing, 43, 402-410. http://dx.doi.org/10.1046/j.1365-2648.2003.02751.x

[39] Edelstein, A. (1990) A Study of Nursing Documentation with a Focus to Improve Both Knowledge and Attitude. Journal of Clinical Nursing, 8, 345-352.

[40] Werner, P. (2004) Reasoned Action and Planned Behavior. In: Peterson, S.J. and Bredow, T., Eds., Middle Range Theories: Application to Nursing Research, Lippincott Williams \& Wilkins, Philadelphia, 125-147.

[41] Martin, A., Hinds, C. and Felix, M. (1999) Documentation Practices of Nurses in Long-Term Care. Journal of Clinical Nursing, 8, 345-352. http://dx.doi.org/10.1046/j.1365-2702.1999.00281.x

[42] Darmer, M.R., Ankersen, L. and Nielsen, B.G. (2004) The Effect of a VIPS Implementation Programme on Nurses' Knowledge and Attitudes towards Documentation. Scandinavian Journal of Caring Sciences, 18, 325-332. http://dx.doi.org/10.1111/j.1471-6712.2004.00289.x 